\title{
SOSIALISASI DAN EFEKTIVITAS KOMUNIKASI PROGRAM PERUMAHANAHAN BERSUBSIDI TERHADAP KESEJAHTERAAN SOSIAL MASYARAKAT
}

\author{
Fitri Syakinah \\ Program Studi Akuntansi, Universitas Garut \\ Jl. Raya Samarang No. 52A, Tarogong Kidul, Garut, 44151 \\ No.HP: 089662092411 \\ e-mail: fitrisyakinah@uniga.ac.id
}

Naskah diterima tanggal 5 Agustus 2020 direvisi tanggal 25 Maret 2021 disetujui tanggal

1 April 2021

\begin{abstract}
Abstrak
Rumah merupakan kebutuhan primer setelah pangan dan sandang. Setiap orang dalam strata sosial ekonomi akan berusaha memenuhi kebutuhan akan rumah. Bagi kebanyakan masyarakat berpengahasilan rendah, pemenuhan kebutuhan dasar ini sangat sulit untuk terpenuhi, yang apabila tidak ada solusi untuk mengatasinya akan menimbulkan masalah kesejahteraan sosial. Untuk mengatasi masalah tersebut, pemerintah beserta bank bekerja sama mengeluarkan skema pembiayaan yang terjangkau bagi masyarakat berpenghasilan rendah. Selain itu program ini diharapkan mampu mengejar kebutuhan perumahan yang terus naik dan sekaligus bisa meningkatkan pertumbuhan ekonomi. Oleh karena itu, dalam studi ini peneliti berniat menganalisis efektivitas program perumahan bersubsidi terhadap kesejahteraan sosial masyarakat di kabupaten Garut. Populasi dalam penelitian ini adalah seluruh konsumen perumahan bersubsidi di kabupaten Garut. Teknik pengumpulan data dilakukan melalui purposive sampling dengan jumlah responden sebanyak 200 . Sementara variabel dalam penelitian ini yang terlibat ada dua. Pertama, program perumahan bersubsidi diperlakukan sebagai variabel laten eksogen. Kedua, kesejahteraan sosial bertindak sebagai variabel laten endogen. Kemudian penelitian ini menggunakan metode deskriptif eksplanatori. Metode PLS-SEM dengan bantuan perangkat lunak XLSTAT 2014 digunakan untuk menjawab hipotesis penelitian. Hasil menunjukkan bahwa program perumahan bersubsidi berpengaruh signifikan terhadap peningkatan kesejahteraan sosial dengan kontribusi sebesar 60,63\%. Hasil penelitian ini diharapkan dapat menjadi evaluasi program perumahan bersubsidi bagi pemerintah, bank, dan stakeholder dalam rangka menyelesaikan masalah kesejahteraan sosial masyarakat.
\end{abstract}

Kata-kata kunci: Kesejahteraan Sosial; Kredit Pemilikan Rumah; Perumahan Bersubsidi; Sosialisasi.

\begin{abstract}
Houses are the primary needs after food and clothing. Everyone in the socioeconomic strata will try to meet the house needs. For most low-income people, the meeting of this basic needs is very difficult to suffice. It will cause social welfare problems if there are no solutions to overcome housing needs in the low-income people. To overcome the social welfare problems, the government and banks work together to issue affordable financing schemes for low-income people. This program is expected to be able to catch up with the increasing housing needs and at the same time be able to increase economic growth. In this study, therefore, the researcher intends to analyze the effectiveness of the subsidized housing program on the social welfare of the people in Kabupaten Garut. The population in this study is all consumers of subsidized housing in Kabupaten Garut. Data collection technique was carried out through purposive sampling with a total of 200 respondents. While the variables in this study involved two variables. First, the subsidized housing program is treated as an exogenous latent variable. Second, social welfare acts as an endogenous latent variable. Then this research uses a descriptive explanatory method. The PLS-SEM method using XLSTAT 2014 software is used
\end{abstract}


to answer the research hypothesis. The results show that the subsidized housing program has a significant effect on improving social welfare with a contribution of $60.63 \%$. The results of this study are expected to be an evaluation of the subsidized housing program for the government, banks, and stakeholders in order to resolve the problem of social welfare.

Keywords: Communication tool; new language; community; variety of languages; shemale.

\section{Pendahuluan}

Pemerintah Kabupaten Garut mengharapkan semua pihak dapat bekerjasama dalam merealisasikan program pemerintah tentang Fasilitas Likuiditas Pembiayaan Perumahan (FLPP) atau rumah subsidi dalam pemberian kredit kepemilikan rumah (KPR). Program ini dapat dijadikan kesempatan bagi masyarakat berpenghasilan rendah atau golongan menengah kebawah untuk memiliki rumah idaman dengan kredit pemilikan rumah (KPR) bersubsidi yang harganya jauh lebih murah dibandingkan dengan KPR normal. Ada sekitar 73 pengembang perumahan di Kabupaten Garut telah memiliki izin untuk kegiatan pembangunan/perumahan dan sudah ada sekitar 20 titik kegiatan yang tersebar di daerah selatan, tengah dan utara. Kegiatan pembangunan yang bersumber dari APBD dilaksanakan oleh Dinas Sosial, untuk yang bersumber dari Bantuan Provinsi dilaksanakan oleh Badan Penanaman Modal dan Prizinan Terpadu ( BPMPT ) dan untuk yang bersumber dari anggaran pusat dilaksanakan oleh Dinas Tata Ruang dan pemukiman ( DISTARKIM ).

Berdasarkan wawancara awal yang tim lakukan dengan BPMPT Garut, dari 73 Perumahan non-subsidi dan subsidi di kabupaten Garut, hampir 50\% dari seluruh jumlah tersebut sudah memiliki IMB dan telah membangun 100-200 rumah. Secara rata-rata, rumah yang telah akad dengan konsumen baru mencapai $75 \%$ rumah, yang telah dibangun, sehingga masih $25 \%$ rumah bersubsidi yang masih belum diminati oleh konsumen. Contohnya seperti pada perumahan bersubsidi di kecamatan Banyuresmi, yang sudah akad baru mencapai 80 rumah dari 100 rumah type 27 yang tersedia.

Berdasarkan wawancara awal, penulis menemukan bahwa konsumen secara umum keberatan akan lokasi perumahan bersubsidi yang letaknya jauh dari perkotaan meskipun dari segi DP yang relatif murah dan rumah layak pakai, di lain pihak para pengembang kesulitan mencari harga tanah yang murah disekitar perkotaan. Pada umumnya kebanyakan konsumen membeli tanah di perkampungan yang lebih relatif murah sehingga berdampak pada harga jual rumah bersubsidi jatuhnya murah pula. Inilah fakta awal dilapangan yang akan diteliti lebih lanjut oleh penulis. Nuansa persaingan merebut konsumen dengan modal yang banyak lebih kental dibandingkan dengan terpenuhinya sarana perumahan bersubsidi untuk masyarakat ekonomi lemah.

Kredit Pemilikan Rumah (KPR) adalah suatu fasilitas kredit yang diberikan oleh perbankan kepada para nasabah perorangan yang akan membeli atau memperbaiki rumah. Di Indonesia, saat ini dikenal ada 2 jenis KPR. Satu, KPR subsidi adalah suatu kredit yang diperuntukan kepada masyarakat berpenghasilan menengah ke bawah 
dalam rangka memenuhi kebutuhan perumahan atau perbaikan rumah yang telah dimiliki. Bentuk subsidi yang diberikan berupa subsidi meringankan kredit dan subsidi menambah dana pembangunan atau perbaikan rumah. Kredit subsidi ini diatur tersendiri oleh Pemerintah, sehingga tidak setiap masyarakat yang mengajukan kredit dapat diberikan fasilitas ini. Secara umum batasan yang ditetapkan oleh pemerintah dalam memberikan subsidi adalah penghasilan pemohon dan maksimum kredit yang diberikan. Dua, KPR non subsidi yaitu suatu KPR yang diperuntukan bagi seluruh masyarakat. Ketentuan KPR ditetapkan oleh bank, sehingga penentuan besarnya kredit maupun suku bunga dilakukan sesuai kebijakan bank yang bersangkutan.

Developer sendiri dapat dibagi 2 (dua) yakni developer perumahan bersubsidi dan developer perumahan biasa. Developer Perumahan bersubsidi adalah developer yang menerima bantuan subsidi, artinya standar harga perumahan yang diberikan terjangkau, dan dikhususkan bagi kalangan menengah ke bawah. Hal ini dilakukan pemerintah agar dalam pelaksanaan pembangunan sosial dapat merata dan setiap strata kalangan masyarakat dapat menikmati dan berkesempatan memiliki tempat tinggal.

Masyarakat yang belum memiliki hunian pribadi dan belum pernah menerima subsidi kepemilikan rumah merupakan target utama dalam Program Sejuta Rumah. Ini karena pemerataan kesejahteraan sedang diupayakan untuk seluruh masyarakat Indonesia agar bisa memiliki hunian pribadi.
Menurut Edi Suharto (2006:3) kesejahteraan sosial juga termasuk sebagai suatu proses atau usaha terencana yang dilakukan oleh perorangan, lembaga-lembaga sosial, masyarakat maupun badan-badan pemerintah untuk meningkatkan kualitas kehidupan melalui pemberian pelayanan sosial dan tunjangan sosial. Dalam Undang- undang No. 11 Tahun 2009, kesejahteraan Sosial adalah kondisi terpenuhinya kebutuhan material, spiritual dan sosial warga negara agar dapat hidup layak dam mampu mengembangkan diri, sehingga dapat melaksanakan fungsi sosialnya. Di dalamnya tercakup pula kebijakan dan pelayanan yang terkait dengan berbagai kehidupan dalam masyarakat, seperti pendapatan; jaminan sosial, kesehatan, perumahan, pendidikan, rekreasi, tradisi budaya, dan lain sebagainya. Menurut M. Syawie (2014:191) mengatakan bahwa pembangunan belum bisa dikatakan berhasil bila salah satu atau dua dari tiga kondisi yaitu kemiskinan, pengangguran, dan ketimpangan masyarakat menjadi lebih buruk meskipun pendapatan perkapita melambung tinggi. Adapun Badan Pusat Statistik Indonesia (2000) menerangkan bahwa guna melihat tingkat kesejahteraan rumah tangga suatu wilayah ada beberapa indikator yang dapat dijadikan ukuran, antara lain tingkat pendapatan keluarga, komposisi pengeluaran rumah tangga dengan membandingkan pengeluaran untuk pangan dan non-pangan, tingkat pendidikan keluarga, tingkat kesehatan keluarga, dan kondisi Perumahan serta fasilitas yang dimiliki dalam rumah tangga. 
Berdasarkan kerangka pemikiran diatas, peneliti merumuskan hipotesis penelitian sebagai berikut

$H_{0}$ : "Tidak terdapat pengaruh efektivitas pelaksanaan program perumahan bersubsidi terhadap kesejahteraan sosial masyarakat kabupaten Garut".

$H_{1}$ : "Terdapat pengaruh efektivitas pelaksanaan program perumahan bersubsidi terhadap kesejahteraan sosial masyarakat kabupaten Garut ".

\section{Metode Penelitian}

Melalui penelitian ini, peneliti bermaksud untuk menyelidiki efektivitas program Perumahanahan bersubsidi terhadap peningkatan kesejahteraan sosial masyarakat. Metode penelitian yang digunakan adalah metode deskriptif eksplanatori, yaitu metode yang berfungsi untuk mendeskriptifkan atau memberikan gambaran terhadap objek yang diteliti melalui data sampel sebagaimana adanya kemudian dilakukan analisis dan dibuat kesimpulan yang berlaku umum.

Studi ini menggunakan dua tipe variabel, yakni variabel eksogen dan variabel endogen. Variabel eksogen berupa program Perumahanahan Bersubsidi, sementara Kesejahteraan Sosial diperlakukan sebagai variabel endogen. Penelitian ini menggunakan instrumen pengukuran dengan mengunakan skala Likert, yang mana responden diminta untuk memilih salah satu jawaban dari lima alternatif jawaban yang tersedia, diberi skor 1-5.

Teknik yang digunakan untuk penarikan sampel adalah purposive sampling, yaitu pemilihan anggota sampel berdasarkan kriteria yang telah ditetapkan oleh peneliti (Sugiyono, 2018:138).
Kriteria yang ditetapkannya adalah seluruh konsumen Perumahanahan bersubsidi di Garut. Cara menentukan ukuran sampel dalam penelitian ini dengan menggunakan rumus slovin dan diperoleh ukuran sampel sebesar 200 konsumen. Data diperoleh secara langsung dengan mendatangi Perumahanahan bersubsidi dan kemudian menyebarkan angket.

PLS-SEM dengan memanfaakan perangkat lunak XLSAT digunakan untuk menguji hipotesis penelitian kami. PLSSEM dipilih karena tidak memerlukan asumsi normalitas (Ghozali, 2014:9). Lebih jauh lagi Ghozali (2014:6) menyatakan bahwa PLS-SEM dapat digunakan ketika teori yang ada relatif masih tentatif atau pengukuran variabel laten/konstruk masih baru. Oleh karenanya, PLS-SEM lebih memiliki keunggulan dibandingkan dengan SEMLisrel.

\section{Hasil Penelitian dan Pembahasan Pembersihan Data}

pencilan terhadap variabel Perumahanahan Bersubsidi, range nilai baku untuk setiap respondennya terletak antara -2,61 hingga $+1,66$. Sementara analisis pencilan terhadap variabel Kesejahteraan Sosial, range nilai baku untuk setiap respondennya terletak antara $-1,36$ hingga $+2,35$. Oleh karena tidak ada nilai baku yang kurang dari -3 dan lebih dari +3 , maka dari kedua analisis tersebut dapat disimpulkan bahwa tidak terdapat pencilan dalam data yang dikumpulkan sehingga kesimpulan yang akan dibuat tidak akan menjadi underestimated atau overestimated. 
Jurnal Komunikasi Universitas Garut: Hasil Pemikiran dan Penelitian

Vol. 7, No. 1, April 2021

Halaman 627-634

\section{Evaluasi Model Pengukuran}

Evaluasi pertama terhadap model pengukuran adalah menguji validitas dari indikator atau nama lainnya variabel manifes, yang hasilnya dapat dilihat dalam tabel 1 berikut ini:

Tabel 1

Metrics dari Convergent Validity

\begin{tabular}{|c|c|c|c|c|c|c|}
\hline Latent variable & $\begin{array}{c}\text { Manifest } \\
\text { variables }\end{array}$ & $\begin{array}{l}\text { Standardized } \\
\text { loadings }\end{array}$ & $\begin{array}{l}\text { Critical ratio } \\
\text { (CR) }\end{array}$ & $\begin{array}{l}\text { Cronbach's } \\
\text { alpha }\end{array}$ & $\begin{array}{l}\text { D.G. rho } \\
\text { (PCA) }\end{array}$ & $\begin{array}{c}\text { Mean } \\
\text { Communalities } \\
\text { (AVE) }\end{array}$ \\
\hline \multirow{7}{*}{$\begin{array}{l}\text { Perumahan } \\
\text { Bersubsidi }\end{array}$} & $\mathrm{X} 1$ & 0.8782 & 28.5778 & \multirow{7}{*}{0.9109} & \multirow{7}{*}{0.9325} & \multirow{7}{*}{0.7308} \\
\hline & $\mathrm{X} 2$ & 0.8428 & 24.7731 & & & \\
\hline & $\mathrm{X} 3$ & 0.9327 & 104.7191 & & & \\
\hline & $\mathrm{X} 4$ & 0.8316 & 32.0567 & & & \\
\hline & $\times 5$ & 0.9224 & 66.4486 & & & \\
\hline & $\mathrm{X} 6$ & 0.9121 & 90.1922 & & & \\
\hline & $x 7$ & 0.6243 & 5.7055 & & & \\
\hline \multirow{12}{*}{$\begin{array}{c}\text { Kesejahteraan } \\
\text { Sosial }\end{array}$} & $\mathrm{X} 8$ & 0.8972 & 47.3800 & \multirow{12}{*}{0.942} & \multirow{12}{*}{0.9503} & \multirow{12}{*}{0.6362} \\
\hline & X9 & 0.7850 & 21.2597 & & & \\
\hline & $\mathrm{X} 10$ & 0.8932 & 70.6330 & & & \\
\hline & $\mathrm{X} 11$ & 0.8972 & 47.3800 & & & \\
\hline & $\mathrm{X} 12$ & 0.8468 & 40.3132 & & & \\
\hline & $\mathrm{X} 13$ & 0.8797 & 46.4401 & & & \\
\hline & $\mathrm{X} 14$ & 0.8789 & 43.0100 & & & \\
\hline & $\mathrm{X} 15$ & 0.6536 & 12.2260 & & & \\
\hline & $\mathrm{X} 16$ & 0.7369 & 17.2088 & & & \\
\hline & $\mathrm{X} 17$ & 0.7648 & 29.2669 & & & \\
\hline & $\mathrm{X} 18$ & 0.6394 & 11.7011 & & & \\
\hline & X19 & 0.6186 & 11.9334 & & & \\
\hline
\end{tabular}

Tabel 1 memperlihatkan bahwa semua nilai standardized loadings untuk masing-masing indikator adalah lebih besar 0,5, baik untuk variabel Perumahanahan Bersubsidi maupun variabel Kesejahteran Sosial. Hal ini menunjukkan bahwa indikator X1 sampai X7 valid mengukur vaiabel Perumahan Bersubsidi dan indikator X8 sampai X19 juga valid mengukur variabel Kesejahteraan Sosial. Sementara signifikansi dari standardized loadings untuk masing-masing indikator dapat dilihat melalui Critical Ratio (CR) yang lebih besar 2. Oleh karena semua nilai CR di atas 2, berdasarkan tabel 1, maka dapat disimpulkan bahwa semua standardized loading adalah signifikan.

Evaluasi keduanya tentang keandalan dari variabel laten Perumahan Bersubsidi dan Kesjahteraan Sosial. Kedua varaibel laten memiliki nilai cronbach's alpha dan D.G rho (PCA) yang lebih besar 0,7 sehingga variabel Perumahan Bersubsidi dan variabel Kesejahteraan Sosial mempunyai keandalan yang tinggi sebagai alat ukur.

Evaluasi ketiga model pengukuran memeriksa sifat convergent validity kedua variabel laten berdasarkan nilai average variance extracted (AVE). Standar nilai dari AVE adalah di atas 0,5. Berdasarkan 
Jurnal Komunikasi Universitas Garut: Hasil Pemikiran dan Penelitian

Vol. 7, No. 1, April 2021

Halaman 627-634

tabel 1, nilai AVE untuk variabel Perumahan Bersubsidi adalah 0,7306 dan untuk variabel Kesejahteraan Sosial adalah 0,6362. Artinya, kedua variabel laten memiliki sifat convergent validity yang baik.

Evaluasi terakhir dari model
pengukuran adalah

Tabel 2 Nilai Cross Loading

\begin{tabular}{ccc}
\hline & Perumahan Bersubsid & Kesejahteraan Sosial \\
\hline $\mathrm{X} 1$ & $\mathbf{0 . 8 7 8 2}$ & 0.7361 \\
\hline $\mathrm{X} 2$ & $\mathbf{0 . 8 4 2 8}$ & 0.7303 \\
\hline $\mathrm{X} 3$ & $\mathbf{0 . 9 3 2 7}$ & 0.6608 \\
\hline $\mathrm{X} 4$ & $\mathbf{0 . 8 3 1 6}$ & 0.6893 \\
\hline $\mathrm{X} 5$ & $\mathbf{0 . 9 2 2 4}$ & 0.7202 \\
\hline $\mathrm{X} 6$ & $\mathbf{0 . 9 1 2 1}$ & 0.7132 \\
\hline $\mathrm{X} 7$ & $\mathbf{0 . 6 2 4 3}$ & 0.4373 \\
\hline \hline $\mathrm{X} 8$ & 0.6992 & $\mathbf{0 . 8 9 7 2}$ \\
\hline $\mathrm{X} 9$ & 0.7117 & $\mathbf{0 . 7 8 5 0}$ \\
\hline $\mathrm{X} 10$ & 0.7402 & $\mathbf{0 . 8 9 3 2}$ \\
\hline $\mathrm{X} 11$ & 0.6992 & $\mathbf{0 . 8 9 7 2}$ \\
\hline $\mathrm{X} 12$ & 0.6410 & $\mathbf{0 . 8 4 6 8}$ \\
\hline $\mathrm{X} 13$ & 0.7307 & $\mathbf{0 . 8 7 9 7}$ \\
\hline $\mathrm{X} 14$ & 0.6882 & $\mathbf{0 . 8 7 8 9}$ \\
\hline $\mathrm{X} 15$ & 0.4302 & $\mathbf{0 . 6 5 3 6}$ \\
\hline $\mathrm{X} 16$ & 0.6076 & $\mathbf{0 . 7 3 6 9}$ \\
\hline $\mathrm{X} 17$ & 0.4647 & $\mathbf{0 . 7 6 4 8}$ \\
\hline $\mathrm{X} 18$ & 0.4029 & $\mathbf{0 . 6 3 9 4}$ \\
\hline $\mathrm{X} 19$ & 0.3800 & $\mathbf{0 . 6 1 8 6}$ \\
\hline & &
\end{tabular}

Tabel 2 memperlihatkan bahwa korelasi indikator X1 dengan variabel Perumahan Bersubsidi (0,8782) lebih besar dibandingkan korelasi indikator X1 dengan variabel Kesejahteraan Sosial (0,7361). Begitupun dengan indikator X2 hingga $\mathrm{X} 7$ berkorelasi lebih tinggi dengan variabel Perumahan Bersubsidi daripada dengan variabel Kesejahteraan Sosial. Sedangkan, indikator X8 hingga X19 berkorelasi lebih tinggi dengan variabel Kesejahteraan Sosial daripada dengan variabel Perumahan Bersubsidi. Dengan kata lain, masing-masing indikator mengukur variabel latennya lebih tinggi dibandingkan variabel laten yang lain. discriminant validity melalui nilai cross loading dan membandingkan nilai AVE dengan kuadrat korelasi antar variabel laten. Nilai-nilai cross loading untuk masing-masing indikator diberikan tabel 2 berikut ini. 
Kesejahteraan sosial mempunyai nilai AVE lebih besar $(0,6362)$ dibandingakn kuadrat korelasi antara variabel Kesjahteraan Sosial dengan variabel Perumahan Bersubsidi (0,6063). Jadi, hasil evaluasi ketiga memperlihatkan bahwa kedua variabel laten memiliki discriminant validity yang baik.

Hasil keseluruhan dari evaluasi model pengukuran menyimpulkan bahwa indikator-indikator yang dibuat valid dan andal dalam mengukur variabel laten Perumahan Bersubsidi dan Kesejahteraan Sosial. Disamping itu, indikator-indikator Perumahan Bersubsidi benar-benar valid dalam mengukur variabel laten Perumahan Bersubsidi bukan yang lain (discriminant validity). Begitupun sebaliknya untuk indikator-indikator Kesejahteraan Sosial memenuhi syarat validitas diskriminan.

\section{Evaluasi Model Struktural}

Evaluasi pertama model struktural adalah pengujian model melalui statistitk uji F dan statistik uji t. Oleh karena dalam penelitian ini hanya melibatkan satu variabel eksogen, maka uji $F$ untuk pengujian secara simultan akan identik dengan pengujian secara individual melalui uji t. Tabel 4 berikut ini memperlihatkan nilai dari statitik uji F.

Tabel 4

Ouput Uji F untuk Uji Secara Simultan

\begin{tabular}{|c|c|c|c|c|c|c|c|}
\hline $\mathrm{R}^{2}$ & $F$ & $P r>F$ & $R^{2}(B o o t s t r a p)$ & $\begin{array}{l}\text { Standard } \\
\text { error }\end{array}$ & $\begin{array}{c}\text { Critical ratio } \\
\text { (CR) }\end{array}$ & $\begin{array}{c}\text { Lower bound } \\
(95 \%)\end{array}$ & $\begin{array}{c}\text { Upper bound } \\
(95 \%)\end{array}$ \\
\hline 0.0063 & 304,9347 & 0.0000 & 0.6093 & 0.0469 & 12.9359 & 0.5145 & 0.7019 \\
\hline
\end{tabular}

Sementara statistik uji t disajikan melalui tabel 5 berikut ini.

Tabel 5

Output Uji t untuk uji secara individual

\begin{tabular}{ccccc}
\hline Latent variable & Value & Standard error & $\mathrm{t}$ & $\mathrm{Pr}>|\mathrm{t}|$ \\
\hline Perumahan Bersubsidi & 0.7787 & 0.0446 & 17.4624 & 0.0000 \\
\hline
\end{tabular}

Kedua uji memberikan nilai $p$-value sebesar 0,000. Apabila ditetapkan $\alpha$ sebesar 0,05, baik melalui uji t maupun uji F, variabel Perumahan Bersubsidi mempunyai pengaruh yang signifikan terhadap variabel Kesejahteraan Sosial. Adapun model persamaan strukturalnya diberikan oleh persamaan berikut ini.

\section{Kesejahteraan Sosial $=\mathbf{0 . 7 7 8 6 6}{ }^{*}$ Perumahan Bersubsidi}

Berdasarkan tabel 4 , besarnya nilai $R^{2}$ adalah 0,6063 atau $60,63 \%$. Artinya, kontribusi Perumahan Bersubsidi terhadap peningkatan Kesejahteraan Sosial sebesar $60,63 \%$, sedangkan sisanya yang $39,37 \%$ oleh variabel-variabel lain. Sesuai dengan kriteria Chin, nilai 0,6063 menunjukkan pengaruh yang moderat.

Untuk menilai kinerja model dalam memprediksi, maka nilai goodness of fit (GoF) absolute akan digunakan untuk memvalidasi kinerja model yang dihipotesiskan. Tabel 6 berikut menyajikan nilai GoF absolut tersebut.

\section{Tabel 6}

Indeks Goodness of Fit (GoF)

\begin{tabular}{lcccc}
\hline & GoF & GoF (Bootstrap) & Standard error & Critical ratio (CR) \\
\hline Absolute & 0.6379 & 0.6405 & 0.0276 & 23.0739 \\
\hline Relative & 0.7713 & 0.7656 & 0.0369 & 20.8744 \\
\hline Outer model & 0.9908 & 0.9890 & 0.0027 & 372.3368 \\
\hline Inner model & 0.7785 & 0.7741 & 0.0369 & 21.0970 \\
\hline
\end{tabular}

Tabel 6 memperlihatkan bahwa nilai GoF absolute dari model adalah 0,6379, yang lebih besar dari 0,36 sehingga tergolong GoF besar, yang artinya bahwa model mempunyai kemampuan yang tinggi dalam hal memprediksi.

\section{Kesimpulan}

Berdasarkan hasil penelitian di atas maka penulis menyimpulkan program 
Jurnal Komunikasi Universitas Garut: Hasil Pemikiran dan Penelitian

Vol. 7, No. 1, April 2021

Halaman 627-634

perumahan bersubsidi harus dilanjutkan karena pengaruhnya signifikan terhadap peningkatan kesejahteraan sosial. Perumahan bersubsidi bukan salah satu faktor yang dapat meningkatkan kesejahteraan sosial. Hal ini bisa dilihat dari kontribusinya hanya mencapai 60,63\%. Maka dari itu sebaiknya pemerintah mengeluarkan kebijakan lain agar dapat meningkatkan kesejahteran sosial seperti: kenaikan UMR, tarif listrik yang murah bagi masyarakat berpenghasilan rendah, pemerintah melakukan intervensi pasar agar harga sembako terjangkau, biaya pendidikan dan kesehatan yang murah.

\section{Daftar Pustaka}

Badan Pusat Statistik. (2000). Indikator sosial ekonomi Indonesia. Jakarta: Badan Pusat Statatistik (BPS).

Ghozali, I. (2014). Structural Equation Modeing: Meode Alternatif Dengan Partial Last Squares (PLS). Semarang: Badan Penerbit Universitas Diponegoro.

Sugiyono. (2018). Metode Penelitian Kuantitatif. Bandung: CV. Alfabeta.

Suharto, E. (2006). Membangun Masyarakat Memberdayakan Rakyat: Kajian Strategis Pembangunan Kesejahteraan Sosial dan Pekerjaan Sosial. Bandung: PT Refika Aditama.

Syawie, M. (2014). Pembangunan Yang Menyejahterakan Masyarakat Indonesia. Sosio Informa, 19(3), 191-204. Diakses dari (https://ejournal.kemsos.go.id/inde x.php/Sosioinforma/article/viewFil e/99/67) 